\title{
Building Practice Teaching System to Cultivate Students' Creative Ability
}

\author{
Yingshun Liu \\ School of Automation \\ Nanjing University of Science and Technology \\ Nanjing, China \\ yingshun@mail.njust.edu.cn
}

\author{
Yue Liu \\ School of Mechanical and Electrical Engineering \\ Changchun University of Science and Technology \\ Changchun, China \\ liuyue@cust.edu.cn
}

\begin{abstract}
Practice teaching is an important form of cultivating students' creative ability and practical ability. It is also an important platform to cultivating student to master scientific method and improve practical ability. Establishing practice teaching system is very significant for the cultivation of the students creative and practical ability. According to the feature of the practice teaching, the practice teaching system is built to cultivate student's combined innovation ability. The constitution and characteristics of practice teaching are analyzed.
\end{abstract}

Keywords-practice teaching; teaching system; creative ability

\section{INTRODUCTION}

In the creative talent cultivation system of mechanical major, practice teaching is an important form of achieve quality education and realization of the goal of talent cultivation. It is also the important method to cultivating student to control scientific method and improve the practical ability. The mechanical major has a strong practicality. In the teaching process, through the various teaching link to do some basic training, improve students' theoretical level and the ability of analyzing and solving problems[1], make understand of the important role that the practice plays in the engineering talents training. Optimizing the design of practice teaching module and perfecting the practice teaching theory system, they are very significant for the cultivation of the student's creative ability and practical ability.

\section{Structure of Practice Teaching System}

Practice teaching is a kind of teaching activities. According to the professional training targets, universities will organize students with a plan in order to achieve perceptual knowledge, improve the practical ability, and enhance the ability to work independently and scientific research ability and so on[2]. The practice teaching of mechanical major consists of course experiment, course design, cognition practice, metalworking practice, production practice, graduation design and all kinds of teaching activities. All these unified teaching activities constitute the practice teaching system.

\section{The Feature of Practice Teaching System}

The purpose of practice teaching system is to cultivate students' creative ability and improve practical ability. It will be designed by following different stages of students' cognition process and different learning stages. It also can promote to optimize teaching contents and teaching methods [3].

Practice teaching system emphasizes the cultivation of the students' creative and practical ability. It will realize coordinated development among the knowledge, capability and inner quality.

Practice teaching system uses modern educational technology, simulation technique in practical teaching by bringing computer technique and modern educational technology to build the new teaching mode.

\section{Establishment of Practice Teaching System}

Practice teaching runs through the whole cultivation process of undergraduate. To cultivate practical ability, scientific and reasonable practice teaching system is required. The core of practice teaching system is the content of practice teaching [4]. The practice teaching runs through the whole teaching system, which has different arrangement in different stages.

\section{A. Course Experiment}

Course experiment connects the theoretical knowledge with the practical knowledge. Through the experiment teaching can cultivate the students' ability to observe problems, analyze and solve problems. It plays an important role in understanding the theoretical knowledge, which can not be replaced.

By building the new education idea, optimizing experiment teaching content, the teaching system is established. There are three levels: "foundation-synthesisdesign ability" [5]. The experiment is renewed by decreasing replication experiment, opening some creative experiments [6]. It is the foundation of ensuring teaching quality and cultivating students' creative ability to look experiment as an independent course. According to the experiment content and the requirement, by increasing creative experiments, making sure the students do it by themselves, which can cultivate students' creative ability and practical ability.

\section{B. Course Design}

Course design is an important design after the course, which is a comprehensive, systematic practice teaching. Through the whole design, the student can use what they have learned to solve problems that they will meet, and they 
can manage a useful method to solve engineering design projects [7].

The subject and content of the course design should be in contact with the engineering design projects [8]. By course design, students can strengthen the awareness of project benefit. In the teaching process, teachers should respect students' imaginations, methods and solutions, make full use of the students' consciousness, creativity and independence. By discussing with the student or talking about in a group, teacher can enlighten them to diverge the thinking, encourage students to think comprehensively, and search for original solution.

\section{Internship}

Internship is an important practice step, it is an effective way for the combination of theory and practice, and it can make the students know more about the factory workers, the situation of factory, and love for their specialty. Internship can provide an important means of perceptual knowledge for their subsequent courses. Undergraduate internship has mainly three forms: cognition practice, metalworking practice and production practice.

Cognition practice can cultivate the students to form a scientific style with a good quality of production, economic concepts and their capacity of combining theory with practice, and also some other basic qualities like safe operation, love of labor as well as cherishing the public property. The practice helps students to establish intuition understanding of various machinery products, construction materials, machine tools and process equipment, to give an in-depth understanding of the mechanical manufacturing industry, and to establish a good engineering awareness and a correct professional thinking in order to lay a certain practice base for the subsequent course teaching.

Metalworking practice is a practice teaching step to have an intimate knowledge of the production process and to cultivate practical ability for students of mechanical major. Through metalworking practice, students can be familiar gradually with mechanical manufacturing process, and master the metal cutting methods and processes, meanwhile, they can learn to operate safely a variety of tools and equipments, to understand new technology in the use of mechanical manufacturing, to master the ability to select simple machining methods and analyzing different technologies during the practice, and to help students to form an ability to understand the drawing symbols and technique conditions.

Production practice teaching is an important practice teaching activity for mechanical engineering major. It is the best opportunity for students to contact society and enterprises, and also the best way to combine theory with practice for them. Mechanical manufacturing is actually a transformation from resources to the products or components. It is a large production system which combines a mass of equipments, materials, manpower and production processes. During the practice, students will understand the general machinery manufacturing process, and familiarize themselves with the common manufacturing methods of machine part. Moreover, they should have initially the ability of choosing processing methods, analyzing and planning all processes during practice. With the advanced manufacturing technology in their knowledge of equipments, they can realize gradually the professional technology and the present production situation as well as the trend of development. In that case, they can finally improve their professional learning enthusiasm for mechanical manufacturing and automation.

\section{Creative Practice}

Besides the routine teaching practice, the activities of practice teaching include also a variety of creative activities in science and technology. Extracurricular activities of science and technology can not only help the students to understand and master the theoretical knowledge, but also help to stimulate students' creative consciousness and ability with the aim to improve students' engineering quality. In accordance with the principles of voluntary, health, diversity, democracy, teachers can establish a association of science and technology or a group of science and technology, and guide actively students to take part in some creative activities [9].Meanwhile, teachers could plan to open elective courses for mechanism creative design, product design and electronic design, etc, and carry out some teaching activities with the priority to students in order to make students to reach their full potential of innovation and to improve students' general ability and overall qualities.

Teachers can organize students to participate in various academic exchange activities and to expand the horizons of scientific thinking and inspiration. Creating the conditions for the students to a variety of scientific research activities, encourages students to participate in science and technology creative activities organized by students, and lets them participate in teachers' scientific research. In another way, the ability of practice and innovation will be improved constantly by organizing students to participate actively in various scientific and technological competitions, letting students show themselves. At the same time, promoting the students to participate in scientific research activities and to combine theory with practice will develop multi-levels and wide-ranging practice teaching activities. Through academic report, promotes students to exchange actively their experiences and lessons during the activities of science and technology innovation, and improves students' scientific research ability under the guidance of experts.

\section{E. Graduation Design}

Graduation design is the main teaching link of cultivating students to apply knowledge and skills, and the main teaching link of engineering technology and scientific research. It is also a kind of comprehensive inspection of college teaching quality, which is the important transition link of the students from school to work. Graduation design 
can strengthen students' modern design method and the creative ability training; enhance the training of students' ability to write scientific papers, and cultivate the students' project practice consciousness and management consciousness.

\section{Construction of Practice Teaching Teacher Team}

Teacher is the dominant of practical teaching system, and the practitioner of this system [10]. To cultivate high quality creative talents, first of all, we must have high quality of experimental teachers and laboratory technicians. For students, mastery of knowledge, ideological and moral cultivation, intelligent development and the formation of creative thinking are all closely linked to teachers' quality. Teachers who guide the engineering practice need to plan carefully all aspects for the practice teaching, and are able to compile practical textbooks, as well as to solve some difficult problems encountered during the engineering practice and innovation for students. Experiment teachers introduce the most advanced experimental techniques, experimental methods and experimental apparatus to students. Meanwhile, they must pay attention to guide students to think and to cultivate their creative ability. To do these works, teachers must be continuous to learn, to practice, and only in this way, they can improve continuously the quality of practical teaching for the mechanical engineering education.

\section{SETting UP EVALUATION SySTEM FOR StUdenTS’ EDUCATIONAL ACHIEVEMENT}

Exam is a mean to reflect the student's ability to grasp knowledge, and also a test on teachers' teaching effect. But only with the test scores as the teaching evaluation target, is not good for mobilizing the enthusiasm of the students. A good evaluation system can not only arouse effectively students' learning motivation, but also conducive to the fair evaluation of teaching effect. The scores of experiment course should be test on the form of practice, experiment report and oral examination; the internship practice is evaluated through students' attendance, practice report and oral examination; for course design and graduation design, teachers should consider the difficulty of design, innovation degree, completion situation and the oral test to give the evaluation results. At the same time, teachers should encourage students' innovation to mobilize students' creative consciousness and engineering consciousness.

\section{REFERENCES}

[1] Li Nan. "The innovation and practice of practice teaching management system.” Journal of Wuxi Institute of Technology, vol. 9, pp. 45-48, March 2010.

[2] Kang Tao, Huang Hua Cai, Peng Quan Kai. “To establish practice teaching system and improve the level of practice teaching." Journal of Jiangxi Agricultural University (Social Science Edition), vol. 3, pp. 138-140, February 2004.

[3] Ji Weixi, Gu Jin, Sun Dayue, Zhang Jiansheng. "Strengthening practice teaching to cultivate creative talents." Experimental technology and management, vol. 25, pp. 20-23, February 2008.

[4] Xing Yuen, Zhang Wenxing. "Practice teaching content and method reform for Mechanical specialty.” China Metallurgical Education, pp. 69-71, March 2011.

[5] Fu Ling. "Strengthening the practice teaching, cultivating engineering students' innovative ability.” The public science and technology, pp 187-188, November 2010.

[6] Zhang Yuping. Practice teaching research for Machinery specialty. Journal of Hubei University of Economics (Humanities and Social Sciences Edition), vol. 7, pp. 188-189, March 2010.

[7] Zhang Minghui,Gao Baohai. "Strengthening practice education, cultivating students innovative design ability." Modern manufacturing technology and equipment, pp. 75-76, June 2010.

[8] Hao Xiaobin. "Deepening the reform of practice teaching, fostering the ability of innovation and practice." Science and technology information, pp. 59-60, June 2010.

[9] Luo Zhiwei. "The exploration of cultivating the students' practice and creative ability.” Journal of Anhui University of Technology (Social Science Edition), vol. 28, pp. 120-121, April 2011.

[10] Wang Jie, Liu Chunyan. "The exploration and practice of practical teaching system for Mechanical specialty.” Journal of Yuncheng University, vol. 29, pp. 76-78, May 2011. 